\title{
SCANNING ELECTRON MICROSCOPIC EVALUATION OF ENAMEL AND DENTIN AFTER LASER VS CONVENTIONAL CLASS V CAVITY PREPARATION IN PRIMARY MOLARS: IN VITRO STUDY
}

\author{
Gihan Mohamed Abuelniel*, Mervat Abdelmoneim Rashed* and Nihal Refaat Kabel ${ }^{* *}$
}

\begin{abstract}
Aim or Purpose: Scanning electron Microscopic evaluation of enamel and dentin after laser (Er, Cr: YSGG) versus conventional class V cavity preparation and after restoration of prepared primary molars with injectable Giomer.

Materials-Methods: Forty primary mandibular second molars were collected. Molars were divided into four equal groups, group (I) class V prepared with the high-speed Diamond bur, group (II) class V prepared with the high-speed Diamond bur and restored with injectable Giomer after adhesive application, group (III) class V prepared with non-contact (Er, Cr: YSGG) laser and group (IV) class V prepared with non-contact (Er, Cr: YSGG) laser and restored with injectable Giomer without adhesive application. Molars were sectioned perpendicular to the long axis of the tooth using a low speed diamond disc under water coolant. Evaluation of enamel and dentin after cavity preparation, and at enamel and dentin / restoration interfaces were observed with Scanning Electron Microscope.
\end{abstract}

Results: In group (I) well-defined smooth cavity floor and walls were almost covered with a debris-like smear layer. In group (II) After acid etching, the smear layer was completely removed and enamel rods or dentinal tubules were clearly visible. In group (III) Irradiated enamel had a characteristic appearance resembling (Lava flow) with open enamel prisms. Protruding dentinal tubules were observed. No visible cracks or carbonization were detected. In group (IV) Laser produced micro-retentive morphological pattern without the production of smearlayer.

Conclusions: It can be concluded that (Er, Cr: YSGG) laser can be an alternative technique for conservative caries removal and provided better bonding of the restoration to primary teeth.

KEYWORDS: Conventional cavity preparation, Laser, Electron Microscope

\footnotetext{
* Pediatric Dentistry, Cairo University, Egypt

** Pediatric Dentistry, Misr University of Science and Technology
} 


\section{INTRODUCTION}

Modern dentistry aims for the approach of minimally invasive techniques. Minimally invasive caries removal is dependent on four important recent concepts: early diagnosis, oral environment modelling based on caries risk assessment, microinvasive cavity preparation and dynamic treatment utilising biologically active materials and modern adhesives. ${ }^{[1]}$

Recently, new technologies have been proposed as an alternative to the conventional mechanical caries removal. High intensity lasers have been widely used by dental professionals that brings the minimal intervention concept into clinical practice. ${ }^{[2]}$

LASER is the acronym for light amplification by stimulated emission of radiation. Albert Einstein first explained its theory in 1917, which became the basis of lasers. After the discovery of ruby laser by Maiman, attempts were conducted in- vitro to investigate the effects of lasers on dental hard tissues and caries using argon, carbon dioxide $\left(\mathrm{CO}_{2}\right)$, and neodymium-doped yttrium aluminium garnet $(\mathrm{Nd}$ : YAG) lasers. ${ }^{[3]}$

Recently, different types of laser are used in dentistry for ablation of hard tissues (enamel, dentine and bone) and for the treatment of soft tissues. It has been reported that laser ablation of enamel and dentine is effective and efficient without any thermal damage to the pulp, and without carbonisation or cracks of the irradiated enamel and dentine. [4] Moreover, many researchers have documented that the use of laser for dental hard tissue treatment including caries removal, cavity preparation, and enamel etching with certain parameters, is both safe and effective. ${ }^{[5,6]}$

However, most lasers are unable to effectively cut biocalcified tissues. $\mathrm{CO}_{2}$ and $\mathrm{Nd}$ : YAG lasers induce surface changes in enamel, but these lasers tend to cause fissuring, cracking, recrystallization or crateriform foci of melting. Moreover, certain types of lasers are able to ablate carious material, but they cannot effectively prepare sound tooth structure and, therefore, are not amenable to cavity preparation. ${ }^{[7]}$ In addition, laser photon energy is complicated by significant elevations in temperature with a potential for deleterious effects on pulpal tissues. ${ }^{[8]}$

Some of these drawbacks have been overcome after the introduction of erbium, chromium: Yttrium, scandium, gallium, garnet (Er, Cr: YSGG) laser in the field of dentistry. This laser system with a wavelength of $2780 \mathrm{~nm}$, frequency of $20 \mathrm{~Hz}$ and pulse energy between 0 and $300 \mathrm{~mJ}$, has FDA approval for several soft and hard tissue procedures. It produces micro explosions during tissue ablation, resulting in macroscopic and microscopic irregularities. The laser energy absorbed by water microdroplets is believed to be partially responsible for hard tissue cutting effects and has been designated as a hydrokinetic system (HKS). ${ }^{[9]}$ Another added advantage regarding the Er, Cr: YSGG laser includes the fact that melting enamel with this laser increases resistance to acid demineralization. Accordingly, the Er, Cr: YSGG laser is the first all-in-one laser that make the economics of providing laser therapy more feasible. ${ }^{[10,11]}$

Literature reports that SEM images of surface topography changes in the enamel and dentine of after irradiation with (Er, Cr: YSGG) laser demonstrated certain alterations that differ between permanent and primary teeth. These changes were attributed to important enamel and dentine anatomic ultrastructure variations between permanent teeth and primary ones. The enamel prisms of primary teeth do not have an orderly spatial pattern compared to those of permanent. The large superficial crystals are irregular due to post-eruption maturation, and often the enamel is aprismatic, which explains why the colour of primary teeth is more opaque. The aprismatic enamel is more frequently found at the interproximal, vestibular and oral aspects of the crown. Moreover, the enamel of primary teeth is less mineralised and more porous.

In addition, the main difference between the dentine of the permanent and primary teeth is related 
to the size and number of the dentinal tubules. The diameter of the dentinal tubules of permanent teeth ranges from $0.5 \mu \mathrm{m}$ to $0.9 \mu \mathrm{m}$ at the enamel-dentine junction, and it increases up to 2-3 $\mu \mathrm{m}$ near the pulp. The diameter of the dentinal tubules of deciduous molars instead varies between 1.77 and $1.80 \mu \mathrm{m}$. The number of dentinal tubules per unit area in permanent teeth is around $15.000-20.000 / \mathrm{mm} 2$ at the enamel-dentin junction, and up to $65.000 / \mathrm{mm} 2$ close to the pulp, while the number of the dentinal tubules per unit area in the primary teeth is lower. The tubules of the primary teeth have a smaller diameter and are more widely spaced compared to the permanent ones. The dentine of deciduous teeth mineralises mainly during the foetal period, and the process continues after birth, which explains why the inorganic component is less abundant in primary teeth. ${ }^{[12]}$

Pediatric dentists who provide restorative care for children are always seeking materials that demonstrate characteristics such as: ease placement, fast setting, high fluoride release, low polymerization shrinkage, good compressive strength, hydrophilicity, and bonding ability to enamel and dentin. Glass ionomers have largely satisfied many of these needs but possessed the drawback of high solubility. Giomers are a new type of restorative material that demonstrates many of the same characteristics as glass ionomers but with clinically improved esthetics and durability. Giomers are composed of milled, silanized glass-ionomer fillers that have undergone the reaction between fluoroalumino silicate glass and polyalkenoic acid prior to milling. The fillers are then used in a base of composite resin which allows fluoride release andrecharge similar to glass ionomers while still retaining the strength and esthetics of composites. ${ }^{[13]}$

The structural differences of enamel and dentine between primary teeth and permanent ones, makes it important to study at SEM the enamel and dentine surface of primary teeth after Er, Cr: YSGG laser irradiation. The aim of this study was to observe by Scanning Electron Microscope (SEM) enamel and dentine surfaces of primary teeth after class $\mathrm{V}$ cavity preparation with Er, Cr: YSGG laser and conventional bur and to examineenamel and dentin / restoration interfacesin both techniques.

\section{MATERIALS AND METHODS}

Forty primary mandibular second molars were extracted or exfoliated. Molars underwent soft tissue debridement. Buccal and lingual enamel surfaces were examined to be caries free. Collected molars were divided into four equal groups:

- Group (I) class V prepared with the high-speed Diamond bur

- Group (II) class V prepared with the high-speed Diamond bur and restored with injectable Giomer after adhesive application

- Group (III) class V prepared with non-contact (Er,Cr:YSGG) laser

- Group (IV) class V prepared with non-contact (Er, Cr: YSGG) laser and restored with injectable Giomer without adhesive application.

In the buccal and lingual surfaces of each tooth two class V cavities were prepared by the same operator, one with the laser system and the other with a high-speed diamond bur.

In group (I), the conventional cavities were prepared by using high-speed diamond bur (Shofu Inc, Kyoto, Japan), in Group (II) class V prepared with the high-speed Diamond bur and restored with injectable Giomer (Beautifil) after the application of single bond universal (3M, ESPE).

In group (III) Laser cavities were prepared by Er, Cr: YSGG laser (Waterlase ${ }^{\circledR}$ iPLUS $^{\mathrm{TM}}$ ) in noncontact mode fig (1), at a distance of $15 \mathrm{~mm}$ with $2780 \mathrm{~nm}$ wave length at $2.25 \mathrm{~W}$ energy (80\% water $60 \%$ air), $15 \mathrm{~Hz}$ frequency, in Group (IV) class V prepared with non-contact (Er, Cr: YSGG) laser where 
terminal part the laser beam is reflected by a prism or metal mirror. The energy is transmitted to the dental surface through an optical window with air/ water jet flow fig (2). Cavities were restored with injectable Giomer (Beautifil) without adhesive application according to manufacturer's instruction.

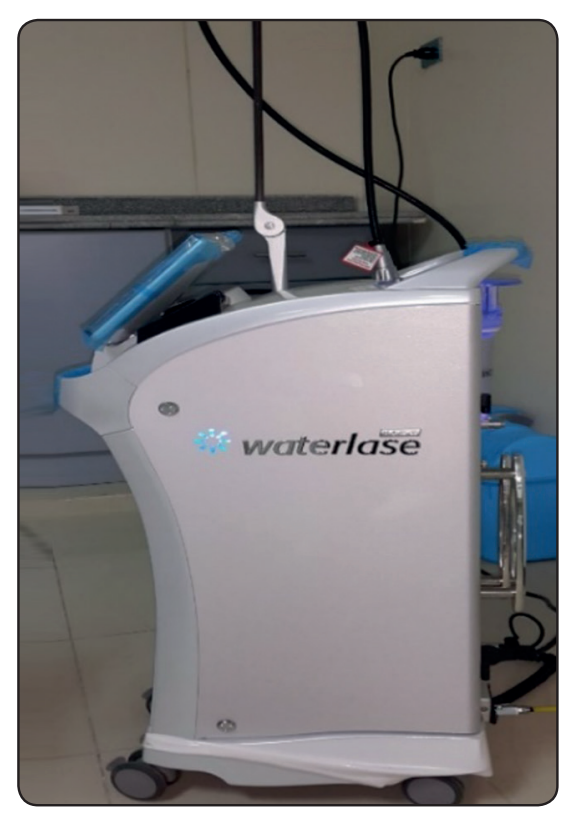

Fig (1) Waterlase ${ }^{\circledR}$ iPLUS $^{\text {TM }}$ laser

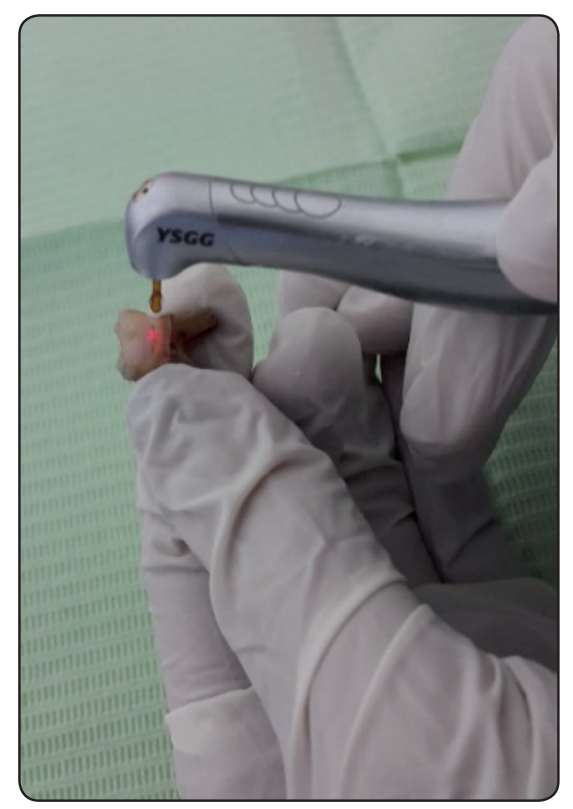

Fig (2) class V prepared with non-contact (Er, Cr: YSGG)
All samples were sectioned with special abrasive disc in buccolingual direction passing through the resulting cavities /and or restorations under water coolant to remove occlusal enamel and expose a flat dentinal surface.

Morphologic evaluation of enamel and dentin after cavity preparation, and at enamel and dentin / restoration interfaces were observed with Scanning Electron Microscope using Model Quanta 250 FEG (Field Emission Gun) attached with EDX Unit (Energy Dispersive X-ray Analyses).

\section{RESULTS}

SEM observation revealed that, relatively flat appearance of cavities prepared by bur. In group (I) cavity surfaces prepared by conventional bur showed well-defined cavity angles, floors and walls, clear margins and relatively smooth cavity floors. SEM observation presented a relatively flat appearance and was almost covered with a debris-like smear layer fig (3); enamel rods were not visible fig (4) and dentinal tubule orifices were plugged fig (5).

In group (II) After acid etching, the smear layer was completely removed and enamel rods fig (6) were clearly visible. In addition, between dentin surface and the restoration a hybrid layer was noticed after the application of adhesive fig (7).

In group (III) Irradiated enamel had a characteristic irregular appearance resembling (Lava flow) with open enamel prisms fig (8). More prominent and protruding dentinal tubules were resulted fig (9). Enamel and dentin, showed no visible cracks or carbonization.

In group (IV) Laser produced irregular and micro-retentive morphological pattern without the production of smear layer that makes these surfaces more suitable for resin composite restorations. Complete interdigitation between the Giomer restoration to both irradiated enamel and dentin was noticed fig (10). 


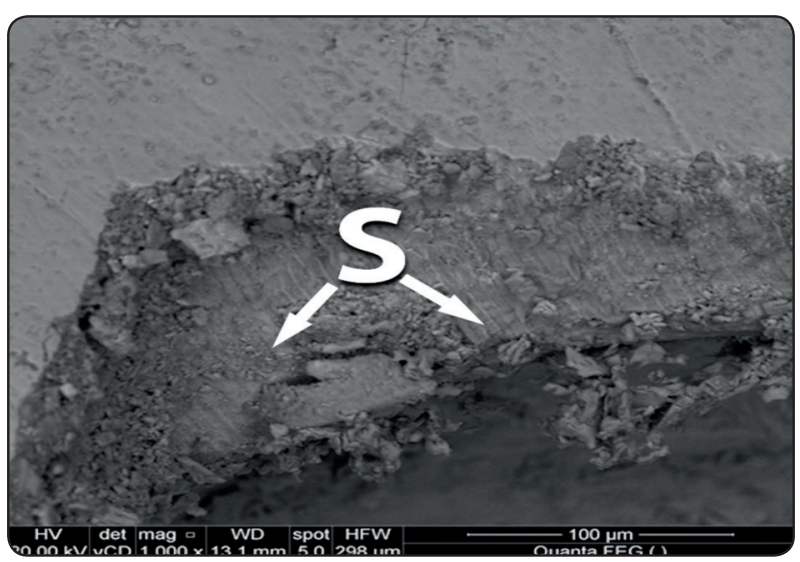

Fig. (3) In cavities prepared by conventional bur SEM observation presented a relatively flat appearance and was almost covered with a debris-like smear layer.

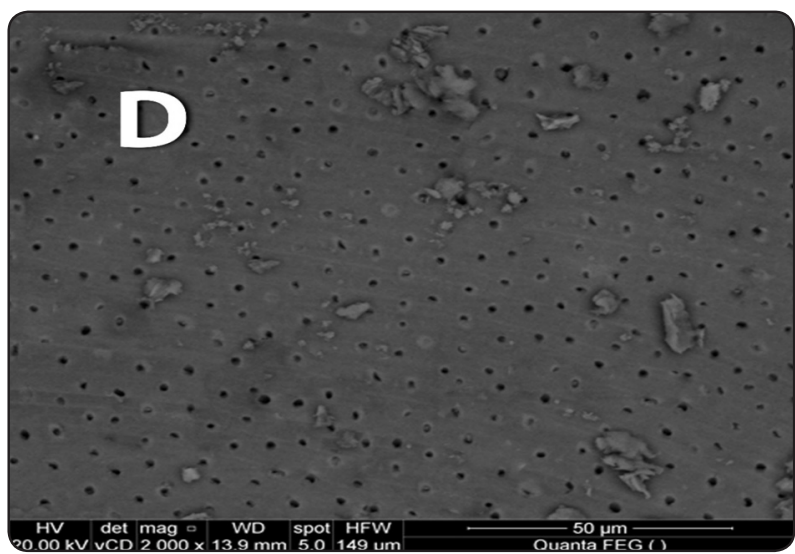

Fig. (5) In cavities prepared by conventional bur dentinal tubule orifices were plugged

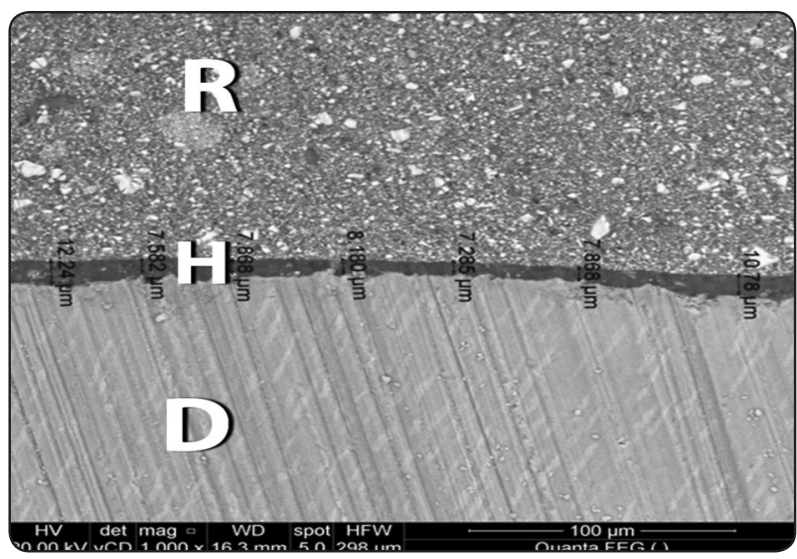

Fig. (7) between dentin surface (D) and the restoration(R) a hybrid layer(H) was noticed after the application of adhesive

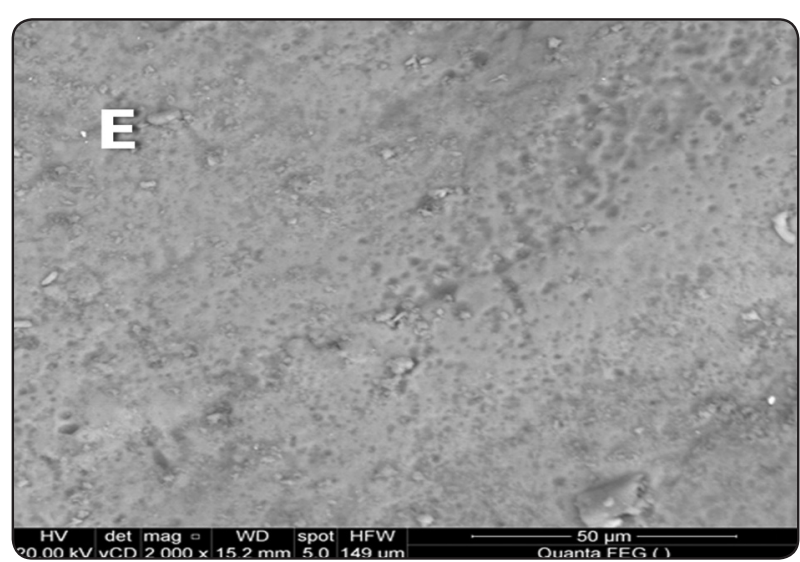

Fig. (4) In cavities prepared by conventional bur enamel rods were not visible

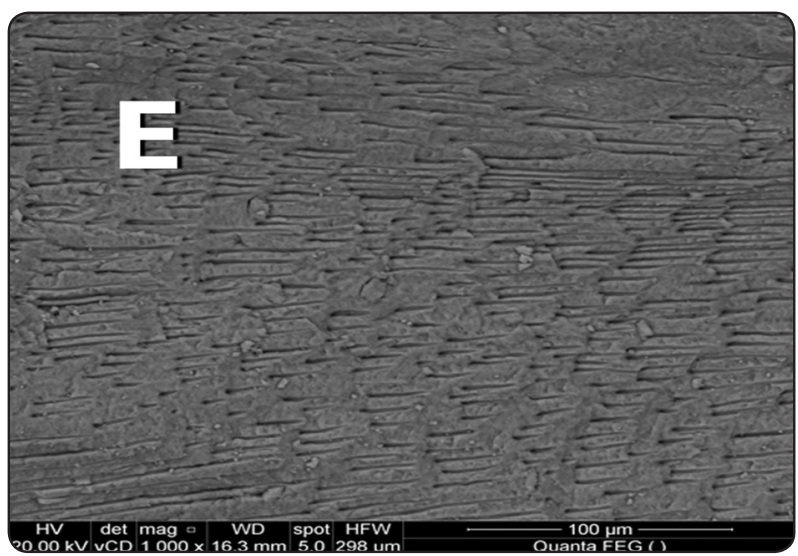

Fig. (6) In cavities prepared by conventional bur after acid etching, the smear layer was completely removed and enamel rods were clearly visible.

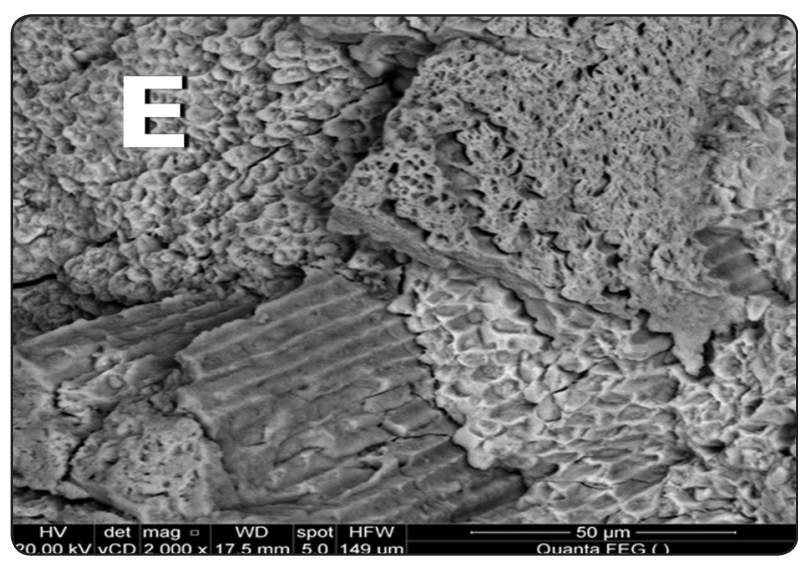

Fig. (8) Irradiated enamel had a characteristic irregular appearance resembling (Lava flow) with open enamel prisms 


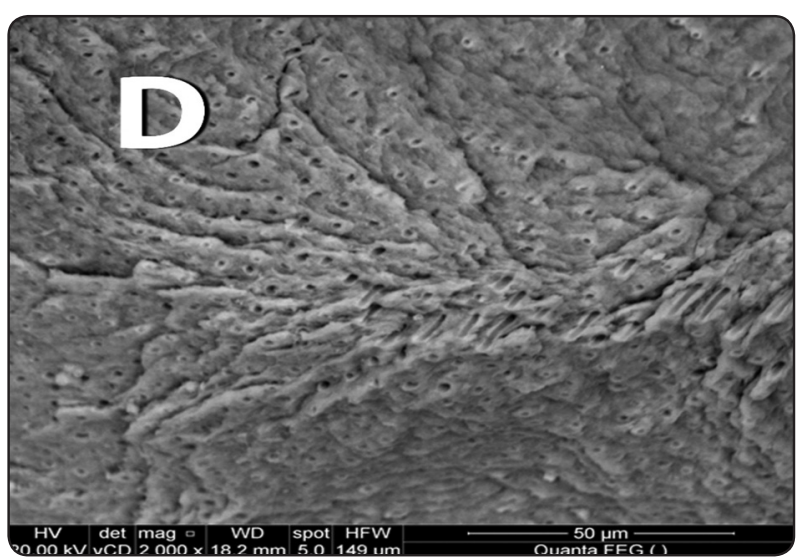

Fig. (9) Irradiated dentin showed more protruding dentinal tubules

\section{DISCUSSION}

Different attempts were conducted in pediatric dentistry looking for more convenient alternatives to mechanical caries removal that could offer less noise, no vibration and no need for the anaesthesia application.

Many studies showed that Er, Cr: YSGG laser was a good substitute for mechanical cutting tools such as burs in conventional cavity preparation with minimal effect on healthy tissue, teeth and surrounding tissues. In comparison to the rotary technique, although cavity preparation with $\mathbf{E r}, \mathbf{C r}$ : YSGG laser may need more time, however, the advantages of laser preparation can overcome such a drawback. ${ }^{[14]}$

In comparison, to high-speed hand pieces and dental burs, teeth preparation by Er, Cr: YSGG reduced sensitivity and significantly reduced discomfort levels at the time of tooth preparation for subjects who declined to receive local anaesthetic. ${ }^{[15,16]}$

SEM- Scanning Electron Microscope is a device that calculates the percentage of different elements in each level through radiating the target surface and analysis of reflected waves, it also facilitates the study of the morphological changes in enamel and dentin after being subjected to different agents or techniques. ${ }^{[17]}$

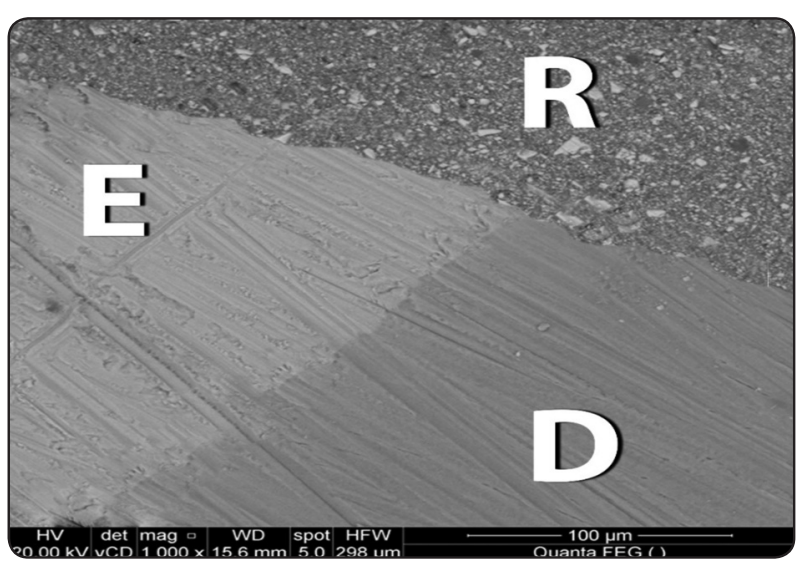

Fig (10) Complete interdigitation between the Giomer restoration (R)to both irradiated enamel (E) and dentin (D) was noticed

The hard tissue removal and cavity preparation with Er, Cr: YSGG laser causes chemical and morphological changes in the dental structure. The rate of the changes has been claimed to be associated with the absorption characteristics of the target and the radiation parameters such as frequency, radiation energy, time and mode of radiation exposure. Waterlase $^{\circledR}$ iPLUS $^{\text {Th }}$ in non-contact mode was used at a distance of $15 \mathrm{~mm}$ with $2780 \mathrm{~nm}$ wave length at $2.25 \mathrm{~W}$ energy ( $80 \%$ water $60 \%$ air), 15 $\mathrm{Hz}$ frequency as recommended by manufacturer's instructions, the parameters used should be lower than those used for permanent. ${ }^{[18]}$

The results of the current study showed surface topography as presented by SEM of cavities prepared using the conventional high-speed and laser are completely different. Surfaces prepared using bur are covered by smear layer as in group (I) but cavities prepared by laser showed complete absence of smear layer as in group (II). The enamel SEM images showed that deciduous lased enamel had the characteristic appearance of a lava flow, similar to the irradiated enamel of permanent teeth as reported in literature. ${ }^{[21,22]}$ This appearance is due to the complete opening of the prism core with a partial destruction of the interprismatic structure. Examining the SEM images of the irradiated dentine of the primary molars revealed irregular 
surface with open dentinal tubules of various diameters and different intertubular and peritubular dentine thickness with the typical aspect of a peritubular collar composed of high mineral dentine concentration. The differences between intertubular and peritubular dentine is not homogeneous for all the samples. This could depend on the exposure time, the different level of teeth hydration or the different laser beam inclination during cavity preparation leading to a variable focus mode. ${ }^{[23]}$

Recently, great progress in dental materials, caries diagnosis and caries removal techniques towards non-invasive and conservative approach was achieved. The introduction of adhesive restorative materials with low viscosity and high resistance to wear turned this principle in to an easier application. GIOMER(BEAUTIFUL) is basically modified glass ionomer. It is a true hybrid of two compounds, Glass ionomer and Composite. The difference of Giomer from Compomer is that, in Compomer variable amount of unhydrated polyacrylic acid is added to the resin matrix and the acid base reaction. The main disadvantage of COMPOMER is less amount of Fluoride release and absence of Fluoride recharging ability. This makes the GIOMER more preferable than compomer. GIOMER uses PRG (Pre-Reacted Glass ionomer) technology where the glass filler particles used are pre-reacted with polyacrylic acid to have a final material that has the properties of both glass ionomer and composites. The properties of GIOMER include, fluoride release, fluoride recharging of glass ionomer, good esthetics, ease of polishing and strength of composite resin. ${ }^{[13]}$

Morphological characteristics of dentin surfaces play an important role in the stability of restoration. Images obtained by SEM, showed that the dentin surface, irradiated by Er, Cr: YSGG laser, had become rough and had more irregularities for sufficient retention of tooth-coloured restorative materials as presented by group (IV). In addition, smear layer had been removed and the dentinal tubules had become opened because of having more water composition. Therefore, the dentin surface, prepared by Er, Cr: YSGG laser, in comparison with bur, has more peritubular dentin, and the zone between peritubular and intertubular dentin is more prominent. ${ }^{[24]}$ Since irradiation with Er, Cr: YSGG laser leads to vaporization of the organic material in dentin; remained mineral component (hydroxyapatite) has a higher surface energy balance. Different microscopic studies have reported that laser causes many surface irregularities the diameter of which in micron. Therefore, laser improves chemical and mechanical bonding strength between dentin and restorative materials through altering the dentin surface with higher surface energy and more irregularities. The results of the present study showed thatenamel undergoes some structural changes during the Er, Cr: YSGG ablation process such as no formation of smear layer, surface irregularities and enamel prisms exposure. These changes are supposed to increase the bond strength of adhesive restorative materials. ${ }^{[25]}$

\section{CONCLUSIONS}

It can be concluded that Er, Cr: YSGG laser can be an alternative technique for conservative caries removal andprovided better bonding of the restoration toprimary teeth.

\section{REFERENCES}

1. Ericson D. The concept of minimally invasive dentistry. Dent Update 2007;34(1):9-10,12-14,17-18.

2. Vitale M, Caprioglio C. Lasers in dentistry-Practical text book; Martina Ed, Bolonga,2010;85-104.

3. Goldman L, Hornby P, Meyer R, Goldman B. Impact of the laser on dental caries. Nature, 1964;203:417.

4. Stabholz A, Zeltser R, Sela M, Peretz B, Moshonov J, Ziskind D. The use of lasers in dentistry: principles of operation and clinical application. Quiz 9492003 Dec; 24(12):935-48.

5. Kornblit R, Trapani D, Bossu M, Muller-Bulla M, Rocca J.P., Polimeni A. The use of Er: YAG laser for caries removal in Paediatric Patients following Minimal Invasive Dentistry Concepts. Eur J. Paediatric Dentistry 2008; Jun 9(2):81-7. 
6. Matsumoto K,Wang X, Zhang C,Kinoshita J. Effect of a novel Er:YAGlaser in caries removal and cavity preparation: a clinical observation. Photomed Laser Surg. 2007 Feb; 25(1):8-13.

7. Rizoiu I, DeShazer L. New laser-matter interaction concept to enhance hard tissue cutting efficiency. SPIE Proc 1994;2134A: 309-17

8. Rizoiu I, Kohanghadosh F, Kimmel AI, Eversole LR. Pulpal thermal responses to an erbium, chromium: YSGG pulsed laser hydrokinetic system. Oral Surg Oral Med Oral Pathol Oral RadiolEndod 1998; 86:220-3.

9. Eversole LR, Rizoiu IM. Preliminary investigations on the utility of an erbium, chromium YSGG laser. J Calif Dent Assoc 1995; 23:41-7.

10. Hossain M, Kimura Y, Nakamura Y, Yamada Y, Kinoshita JI, Matsumoto K. A study on acquired acid resistance of enamel and dentin irradiated by Er, Cr: YSGG laser. J Clin Laser Med Surg 2001; 19:159-63.

11. Dederich DN, Bushick RD; ADA Council on Scientific Affairs and Division of Science; Journal of the American Dental Association. Lasers in dentistry: Separating science from hype. J Am Dent Assoc 2004; 135:204-12.

12. Sturdevant's Art \& Science of operative dentistry. Fourth edition. Copyright 2002 by Mosby, Inc.

13. Nakamura N, Yamada A, Iwamoto T, et al. Two-year clinical evaluation of flowable composite resin containing prereacted glass-ionomer. Ped Dent J. 2009;19(1):89-97.

14. Hibst R. Lasers for Caries Removal and Cavity Preparation: State of the Art and Future Directions. J Oral Laser Appl 2002; 2: 203-212.

15. Kara C, Orbak R. Comparative evaluation of Nd: YAG laser and fluoride varnish for the treatment of dentinal hypersensitivity. J Endod. 2009; 35:971-4.

16. Hadley J, Young DA, Eversole LR, Gornbein JA. A laser-powered hydrokinetic system for caries removal and cavity preparation. J Am Dent Assoc. 2000; 131:777-85.

17. Shahabi S, Zendedel S. Atomic analysis and hardness measurement of the cavity prepared by laser. Lasers Med Sci 2010; 25: 379-383.

18. Zhang, S., Chen, T. \&Ge, L. Scanning electron microscopy study of cavity preparation in deciduous teeth using the Er: YAG laser with different powers.Lasers Med Sci 2012; 27: 141 .

19. Kohara EK, Hossain M, Kimura Y, Matsumoto K, Inoue M, Sasa R Morphological and microleakage studies of the cavities prepared by Er: YAG laser irradiation in primary teeth. J Clin Laser Med Surg 2002; 20:141-147.

20. Kornblit R, Bossù M, Mari D et al. Enamel and dentine of deciduous teeth Er: YAG laser prepared. A SEM study. Eur J Paediatr Dent 2009; 10(2):75-82.

21. Ying D, Chuah GK, Hsu CY. Effect of Er: YAG laser and organic matrix on porosity changes in human enamel. J Dent 2004 Jan; 32(1):41-46.

22. Freitas PM, Navarro RS, Barros JA, Eduardo CP. The use of laser for cavity preparation: An SEM evaluation. Microsc. Res. Tech. 2007; 70:803-808.

23. Delmé KI, De Moor RJ. Scanning electron microscopic evaluation of enamel and dentin surfaces After Er: YAG laser preparation and laser conditioning. Photomed Laser Surg 2007; 25:393-401.

24. Hossain M, Nakamura Y, Murakami Y, Yamada Y, Matsumoto K. A comparative study on compositional changes and Knoop hardness measurement of the cavity floor prepared by Er: YAG laser irradiation and mechanical bur cavity. J Clin Laser Med Surg 2003; 21: 29-33.

25. Hossain M, Nakamura Y, Yamada Y, Murakami Y, Matsumoto K. Microleakage of composite resin restoration in cavities prepared by Er, Cr: YSGG laser irradiation and etched bur cavities in primary teeth. J. clinical Pediatric Dent. 2002 Mar;26(3):263-268. 